\title{
Filipino consumer preferences for peanut butter
}

\section{F. C. F. Galvez', L. S. Palomar², M.L. dL. Francisco', A. O. Lustre ${ }^{3}$, and A. V. A. Resurreccion ${ }^{4}$}

'Department of Food Science and Nutrition, College of Home Economics, University of the Philippines at Diliman, Quezon City 1101, Philippines;

${ }^{2}$ Department of Food Science and Technology, College of Engineering and AgriIndustries, Leyte State University, Baybay, Leyte 6521-A, Philippines: ${ }^{3}$ Food Development Center, National Food Authority, FTI Complex, Taguig, Metro Manila. Philippines; ${ }^{4}$ Center for Safety and Quality Enhancement, Department of Food Science and Technology, Georgia Agricultural Experiment Station, University of Georgia, Griffin, GA 30223- 1797, U. S.A.

\section{ABSTRACT}

Galvez, F. C. F., L. S. Palomar, M.L. dL. Francisco, A. O. Lustre, and A. V. A. Resurreccion 2006. Filipino consumer preferences for peanut butter. Ann Trop. Res. 28(1):58-69

One-on-one interviews were conducted nationwide in different regions in the Philippines. A total of 387 households participated in the survey. Most households bought peanut butter at least once a month. Results indicated that sweetness, brand. and price of product were the major factors that influenced the choice of Filipino consumers of peanut butter to buy. There was some indication of "brand loyalty" Approximately two-thirds of Filipino families actually preferred the firm (stabilized) type of peanut butter even when they bought the flowing (not stabilized) type because of lower price of the latter. Color was not a major factor considered by Filipino consumers in buying peanut butter. Some consumers $(50 \%)$ liked added flavor (chocolate or fruit jelly) in their peanut butter and were willing to pay more than $\mathrm{PhP} 1.00$ additional price for it. Filipino consumers were aware and knowledgeable about vitamin $\mathrm{A}$ and the presence of vitamin A-fortified food products in the market. They indicated that the would buy vitamin A-fortified peanut products when these were made available. Most of them $(>90 \%)$ were willing to pay more than $\mathrm{PhP} 0.25$ additional price with a large proportion who were willing to pay more than $\mathrm{PhPl} .00$ additional price.

Keywords: consumers, food preference, vitamin A-fortified.

Correspondence: L.S. Palomar Present Address: Department of Food Science and Technolog: College of Engineering and Agri-Industries, Leyte State University, Visca, Baybav, Leyte 6521-A Philippines. 


\section{WNTRODUCTION}

Consumers play a very important role in the success of products and es technologies in the market. A high level of acceptance to consumers is an enential pre-requisite for such success. Products succeed in the market hecruse they offer attributes perceived by consumers as pertinent to felt needs unif desires.

It is important not only to describe what consumers eat but also to unierstand them in their own terms with regards to what, how and why they try and eat. Attempts to introduce new items into a food system are likely to fil unless these are fully understood. The acceptability of a new food product mas be improved if the item can be structurally integrated into a culturally furmiliar dish or made analogous to an old food by manipulating color, texture, inipe or other sensory attributes that define the essence of food. Understanding existing food habits allow comprehension on how change is likely to occur und may be useful in planning interventions as well as in foreseeing the ended consequences.

The food that is eaten depends largely on the food that people prefer. Food preference is thus the degree of like or dislike for a food (Pilgrim, 1957). Ainong all peanut products in the Philippines, peanut butter was found to be the most liked by consumers (Garcia et al., 1990). The national average monthly household consumption rate for peanut butter in the Philippines was $42 \mathrm{~g}$ valued at P27.10, or an equivalent of about $73 \mathrm{~g}$ at the per capita level ed at P4.70. Ilocos Region, Northern Mindanao, and Eastern Visayas were the 3 leading household consumers of peanut butter, with an abcve average puntity consumption from $575 \mathrm{~g}$ to $641 \mathrm{~g} / \mathrm{month}$. At the per capita level, the wh three consumers were Ilocos Region, Central Mindanao and Southern danao, whose respective demands ranged from 95 to $105 \mathrm{~g} / \mathrm{month}$. em Visayas was the lowest household and percapita consumer, reporting $289 \mathrm{~g}$ and $42 \mathrm{~g} / \mathrm{month}$, respectively. The national average frequency of mption was approximately twice a month.

There was a need to identify new market opportunities for peanuts and peanut based products in the Philippines. In addition, efforts toward fortification If peanut butter with micronutrients, such as vitamin A, directed towards witfessing the concerns and needs of consumers when their attitudes, behaviors, 
and concerns on such fortification were needed.

The objectives of this study were to determine consumer perception and preferences for and consumption patterns of peanut butter in the Philippines and to document knowledge, attitudes, behaviors and concerns of Filipino consumers on vitamin A fortification of peanut butter in the Philippines.

\section{MATERIALS AND METHODS}

\section{Questionnaire development}

A survey questionnaire was designed and administered in a one-on-one interview. The interviewers were trained on the questionnaire and on interview techniques by role-playing. A pre-test was conducted in the Metro-Manila area among 15 households. The questionnaire was revised based on the results of the pre-test. The final questionnaire, written in English but translated into the dialects, was structured into four parts: (a) demographic and socio-economic questions, (b) peanut butter consumption of households; (c) peanut butter preferences; and (d) knowledge, attitude and behavior towards vitamin A fortification and (e) how much they were willing to pay for all improvements that would be introduced in the product.

\section{Data collection and processing}

Nationwide one-on-one interviews were conducted in different regions and islands of the Philippines. Only those respondents who answered "Yes" to the recruitment screener question "Do you buy peanut butter?" were taken as participants in the survey. At least 100 respondents were taken from the MetroManila area, and at least 50 respondents were interviewed for every region visited outside of the Metro-Manila area. Both low-income families (with family incomes less than $\mathrm{PhP} 10,000$ per month) and middle-income families (with family incomes more than $\mathrm{PhP} 10,000$ but less than $\mathrm{PhP500,000}$ per month) were adequately represented in the total number of respondents. At least 25 of the respondents for every region represented each of the two income levels.

For questions on peanut butter preferences, respondents were shown 
Himples of representative products not identified by brand. Samples in petri thates were shown when questions on peanut butter color preferences were witet pale brown (firm or stabilized type) brown (traditional or unstabilized) und dark brown (a laboratory-prepared sample from over-roasted peanuts.

The data collection period lasted for three months. Only completed mestionnaires were included; $100 \%$ of the data were verified and frequency untysis was done on the data gathered.

\section{IESULTS AND DISCUSSION}

\section{Demographic information}

A total of 252 middle-income households (MI) and 135 low-income eholds (LI) participated in the survey with the major food buyer in the ehold participating as the respondents including 15 families that participated $g$ the pre-testing of the questionnaire.

Demographic information of the survey showed $75 \%$ of all respondents 37 MI and $103 \mathrm{LI}$ ) were between $20-50$ years old while $13 \%$ (32 MI and TLI) were 51-60 years old. The rest (12\%) were either below 20 years old er 60 years old. Forty-seven per cent of the MI respondents had monthly firmily incomes above $\mathrm{PhP} 20,000,23 \%$ had monthly incomes of $\mathrm{PhP} 15,000$ PP20,000 and 30\% have monthly incomes of PhP10,000-PhP15,000. In the case of the LI respondents, $69 \%$ had monthly family incomes of PhP5,000ThP9,999 and 30\% had monthly family incomes of PhP1,000-PhP4,999.

On the monthly family expenditure on food, approximately $40 \%$ of the and $80 \%$ of the LI spent a maximum of PhP5,000 every month for food. Firy-three per cent of the MI spent about PhP5,000-PhP10,000 while only afs of the LI spent this much on food every month. The remaining MI (16\%) nent more than $\mathrm{PhP} 10,000$ for food every month. In both the MI and LI furmilies, the wife bought and cooked the food ( $53 \%$ for $\mathrm{MI}$ and $60 \%$ for $\mathrm{LI}$ ). The husband occasionally participated in these activities ( $14 \%$ for $\mathrm{MI}$ and 45 for $\mathrm{LI}$ ). The presence of domestic helpers was very apparent in the MI 25) in which they were the ones who bought and cooked the food. 


\section{Consumption of peanut butter}

Table 1 shows the peanut butter consumption patterns of Filipinos. All $(100 \%)$ respondents bought peanut butter as this was the pre-enterview requirement. Most of the respondents bought peanut butter once a month, (for MI: $38 \%$ buy peanut butter once a month, $27 \%$ twice a month, $7.0 \%$ once a week; for LI: $35.5 \%$ buy peanut butter once a month, $20 \%$ twice a month, and $19 \%$ once a week). It was noted that more LI ( $19 \%)$ bought peanut on a weekly basis than the MI $(7.0 \%)$. This may probably be due to the capability of MIs to buy and use expensive spreads other than peanut butter on a weekly basis and buy peanut butter in large quantities every month. The LI has limited budget thus they can only afford the traditional peanut butter as their sandwich spread.

Results indicated that taste (75\% MI and 70\% LI), brand (44\% for MI and $42 \%$ for $\mathrm{LI}$ ), and price ( $21 \% \mathrm{MI}$ and, $10 \% \mathrm{LI}$ ) were the three major factors that influence the choice of the peanut butter to buy across all regions visited. Philippine consumers basically preferred sweet-tasting firm stabilized (type) peanut butter. Texture was considered by few respondents (23\% MI and $11 \% \mathrm{LI}$ ) as basis of choice in the purchase of peanut butter. Majority of Filipino consumers bought the local peanut butter most of the time ( $85 \%$ for $\mathrm{MI}$ and $98 \%$ for $\mathrm{LI}$ )

The respondents were likewise asked who among the family members consumed peanut butter the most. Surprisingly, it was not the kids ( 12 years old and younger) who ate peanut butter the most. Rather, the older members of the families ( 13 years old and older), in $80 \%$ of both the MI and the LI, were the major consumers of peanut butter in Filipino families.

\section{Peanut butter preferences}

When questions on peanut butter preferences were asked, the respondents were shown samples of representative products. Samples presented were not identified as to the brand. For questions on color preferences, samples shown were in petri plates.

As was mentioned earlier, approximately two-thirds of Filipino families preferred the firm type (stabilized) peanut butter (64\% MI and 63\% LI) over the "flowing" type (not stabilized) or the traditional Philippine peanut butter 
Table 1. Peanut butter consumption patterns of Filipinos $(\mathrm{N}=387)$

\begin{tabular}{llllll}
\hline \multirow{2}{*}{ Factors } & \multicolumn{2}{c}{ Middle Income $^{1}$} & & \multicolumn{2}{c}{ Low-Income $^{2}$} \\
$\begin{array}{l}\text { I. Frequency of } \\
\text { consumption of } \\
\text { preanut butter }\end{array}$ & & & & \\
& & & & & \\
Prequency & & & & \\
Once a Week & 18 & 7.1 & & 26 & 20.3 \\
Twice a Month & 67 & 26.6 & & 27 & 35.5 \\
Once a Month & 96 & 38.1 & 48 & 25.2 \\
Occasionally & 71 & 28.2 & 34 &
\end{tabular}

II. Basis of choice of what peanut butter to buy

Brand

Availability

Taste

Color

Texture
111

88

52

189

29

58
44.0

34.9

20.6

75.0

11.5

23.0
57

70

26

95

9

15

42.2

51.8

19.2

70.4

6.7

11.1

III. Peanut butter brand usually bought

Local
Imported
No answer
Member of the
household who
consumes peanut butter

Mother

Father

60

23.8

21

15.6

Children

$>20 \mathrm{yrs}$

85

33.7

31

23.0

13-19 yrs old

71

28.2

31

23.0

7-12 yrs old

44

17.5

1-6 yrs old

32

12.7

20) $\quad 14.8$

14

10.4

'Monthly income of $>$ PHP 10,000-5000,000

${ }^{2}$ Monthly income of $<$ PHP 10,000 
(Table 2). The reasons cited included spreadability, flavor and taste. Filipino consumers liked the more peanutty flavor of the firm type. This result may be an indication of the possible influence of quality impressions on imported products. Filipinos have the tendency to think that imported products (particularly from the US) have better quality and so they tend to prefer these products. "Flowing" type peanut butters exhibit oil separation upon storage with the oil staying on top of the product. The respondents that preferred the "flowing" type peanut butter were asked which kind they prefer, those with oil separation or those without oil separation. Majority of Filipino consumers prefer "flowing" type peanut butter with no oil separation (63\% MI and 52\% LI).

Color did not seem to influence Filipino consumer preference for peanut butter preference of the stabilized peanut butter which does not have any oil separation. The most preferred color was brown ( $77 \%$ for MI and $62 \%$ for LI). Samples presented for color preferences included the following: pale brown (firm type), brown ("flowing" type), and dark brown (a laboratory-prepared sample from over-roasted peanuts). Pale brown color was preferred by $15 \%$ MI and 33\% LI.

When asked if they want peanut butter with added flavor, the respondents were equally divided. Fifty per cent (for both MI and LI) wanted added flavor and $50 \%$ did not like added flavor in their peanut butter. Most of those who liked added flavor in peanut butter would like to have either chocolate or jelly added to the peanut butter. When asked if they would buy peanut butter with added flavor even when the price was increased to more than $\mathrm{PhP} 0.25$ $\mathrm{PhP1}$.00, the respondents were equally divided. Fifty percent (for both MI and LI) wanted added flavor in their peanut butter preferably chocolate, and $50 \%$ did not like the flavor. Chocolate flavor had been incorporated into peanut products in the Philippines such as peanut-chocolate bars popularly called 'Choc-nut' and chocolate added peanut candies.

\section{Knowledge, attitudes and behavior toward vitamin A fortification}

All respondents have heard about vitamin A, or claimed to know something about it. When asked specifically what they knew about vitamin A, 
Filipino consumer preferences for peanut butter

Table 2. Peanut butter preferences of Filipinos1 ( $N=387)$.

\begin{tabular}{|c|c|c|c|c|}
\hline \multirow[t]{2}{*}{ Factors } & \multicolumn{2}{|c|}{ Middle Income ${ }^{2}$} & \multicolumn{2}{|c|}{ Low-Income ${ }^{3}$} \\
\hline & Frequency & $\%$ & Frequency & $\%$ \\
\hline \multicolumn{5}{|l|}{$\begin{array}{l}\text { Preference for type of } \\
\text { peanut butter }\end{array}$} \\
\hline Traditional (Unstabilized) & 92 & 36.5 & 51 & 37.8 \\
\hline Firm (Stabilized) & 160 & 63.5 & 84 & \\
\hline \multicolumn{5}{|l|}{$\begin{array}{l}\text { II. Reason for peanut butter } \\
\text { preference }\end{array}$} \\
\hline Spreadability & 156 & 61.9 & 85 & 63.0 \\
\hline Flavor & 62 & 24.6 & 43 & 31.8 \\
\hline Taste & 136 & 54.0 & 69 & 51.1 \\
\hline Sweetness & 59 & 23.4 & 39 & 28.9 \\
\hline Color & 37 & 14.7 & 14 & 10.4 \\
\hline
\end{tabular}

III. Peanut butter color preference

Pale brown

39

15.5

45

33.3

Brown

Dark brown

194

77.0

84

62.2

19

7.5

6

4.4

IV. Peanut butter sweetness

$\begin{array}{lllll}\text { Not sweet } & 54 & 21.4 & 24 & 17.8 \\ \text { Sweet } & 190 & 75.4 & 95 & 70.4 \\ \text { Very sweet } & 1 & 0.4 & 4 & 2.9 \\ \text { No answer } & 7 & 2.8 & 12 & 8.8\end{array}$

V. Peanut butter texture preference

Smooth and creamy 
Table 2 continued....

\begin{tabular}{llllll}
\hline Factors & \multicolumn{2}{l}{ Middle Income $^{2}$} & & \multicolumn{2}{c}{ Low-Income $^{3}$} \\
& Frequency & $\%$ & & Frequency & $\%$ \\
\hline VI. Response to added & & & & \\
flavor to peanut butter & & & 66 & 58.9 \\
& 135 & 53.6 & 69 & 51.1 \\
Yes & 117 & 46.4 & & 69
\end{tabular}

VII. Response to what flavor should be added to peanut butter

Chocolate

Jelly (fruit)

Others

VIII. Response to the additional

Price respondents were willing to pay for added flavor to peanut butter

\begin{tabular}{lllll}
$<0.25$ & 8 & 5.9 & 12 & 17.6 \\
$0.25-<0.50$ & 15 & 11.1 & 11 & 16.2 \\
$0.50-<0.75$ & 9 & 7.4 & 6 & 8.8 \\
$0.75-<1.00$ & 21 & 6.7 & 6 & 8.8 \\
1.00 & 65 & 15.6 & 11 & 16.2 \\
$>1.00$ & 7 & 48.1 & 16 & 23.5 \\
No response & & 5.2 & 7 & 10.6 \\
\hline
\end{tabular}

' Samples shown to respondents :a) unstabilized local brand (traditional, brown, sweet); b) stabilized local brand (firm, pale brown, not sweet; and c) laboratory prepared (dark brown).

${ }^{2}$ Monthly income of $>$ PHP 10,000-500,000

${ }^{3}$ Monthly income of $<$ PHP 10,000 
$41 \%$ of the MI respondents surprisingly answered they did not know specific benefits of this vitamin, while only $20 \%$ of the LI respondents did not know specific facts about vitamin A. Forty-six per cent of MI and 55\% of LI knew that vitamin A was "good for the eyes". Other information about this vitamin that the respondents cited were that vitamin $A$ is present in yellow foods, it is good for the skin, and it fights cancer.

More than $75 \%$ of all MI and LI that participated in the survey were aware of the presence of vitamin A-fortified foods in the Philippine market (Fig. 1). Only $2 \%$ did not buy vitamin A-fortified food products. The reasons cited for buying vitamin A-fortified food products included nutrition, necessity, and convenience, being delicious, or simply liking it.

Vitamin A fortified products in the market gained popularity due to the extensive campaign of the Philippine government in the mid-90's on the eradication of nutrient deficiencies including vitamin A deficiency in children. The Sangkap Pinoy Seal Program 9SPSP which started in 1995 was a program to encourage food manufacturers to fortify their products with essential micronutrients such as vitamin A, iron and iodine. Food manufacturers in the Philippines were authorized by the Department of Health (DOH) to use seal of acceptance known as SPS on products that were fortified with micronutrients such as vitamin $\mathrm{A}(\mathrm{DOH}, 2000)$. Early studies revealed that $97 \%$ of Filipinos use fortified foods in their daily meals (Samonte, 2002).

When asked if they would buy vitamin A-fortified peanut butter, almost all ( $98 \%$ for MI and $96 \%$ for LI) would buy the product. Majority of the respondents ( $99 \%$ for $\mathrm{MI}$ and $90 \%$ for $\mathrm{LI}$ ) indicated that they were willing to pay more than $\mathrm{PhP} 0.25$ additional price for vitamin A-fortified peanut products.

\section{CONCLUSION}

Filipinos prefer the stabilized or firm type of peanut butter over the oldfashioned unstabilized or "flowing"-type peanut butter. However, the taste (sweetness), brand and cost/price of the product, which were the major factors affecting the choice of the peanut butter to buy, make the local "flowing" type brands still more popular to consumers. There is also some indication of brand-loyalty. Although color does not affect the choice of peanut butter to 


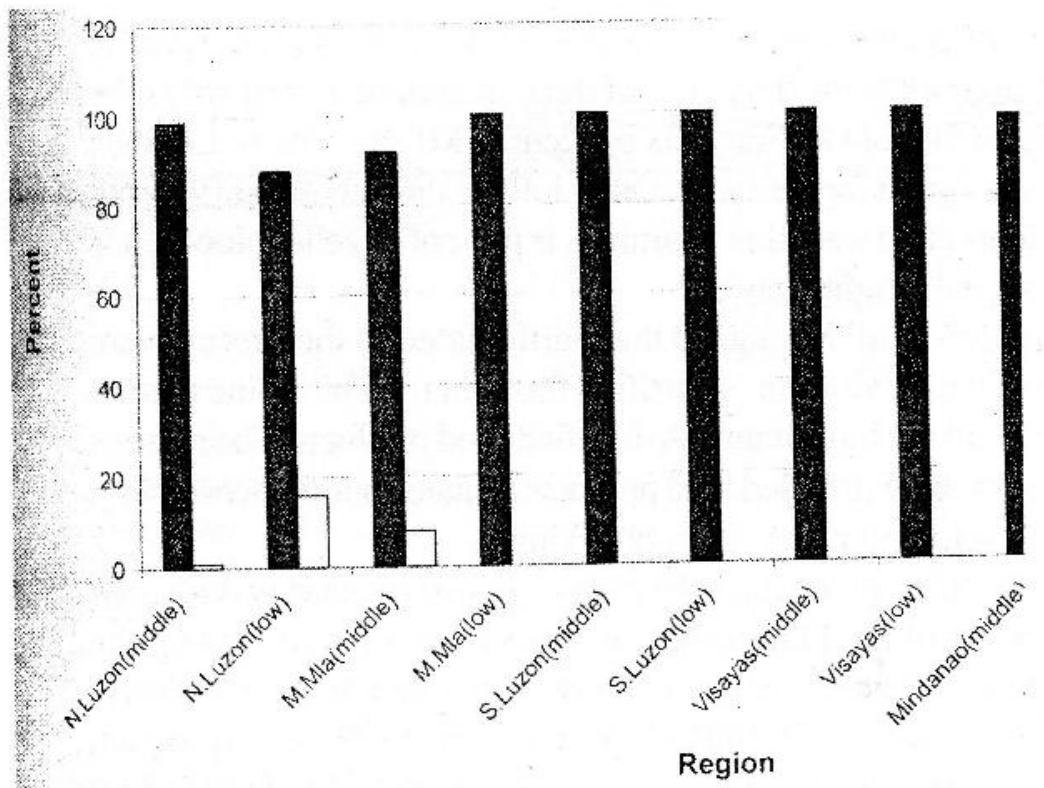

Figure 1. Response of Filipino consumers in different regions on their awareness reagrding Vitamin A fortified foods available in the market ( N. Luzon, and S. Luzon stands for Northern Luzon and Southern Luzon respectively and M.Manila stands for Metro Manila) 
buy as much as the other factors do, Filipinos prefer the brown color of the local "flowing" type peanut butter. Filipino consumers would like to have additional flavor (specifically, chocolate flavor) in peanut butter and they are willing to pay additional price for this. In general, Filipino consumers are aware and knowledgeable about vitamin $\mathrm{A}$ and the presence of vitamin A-fortified products in the market. They are already buying these products and they will buy vitamin A-fortified peanut butter when this is made available even at higher prices.

\section{REFERENCES}

DOH. 2000.The Philippine food Fortification Program. [available online at http:// www.doh,gov.ph/foodfortification/summary.htm]

GARCIA, V. V., S. M. RUBICO, R. C. ARENAS, , AND R. D. VALMONTE. 1990. Peanut Consumption Patterns in the Philippines. Los Banos, Laguna: PCARRD, UPLB, P-CRSP.

PILGRIM, F. 1957. The components of food acceptance and their measurement. Ame. J of Clinic. Nut. 5:171.

SAMONTE, H. PB. 2000. Survey reveals popularity of fortified foods. [available online at http://www.sti.dost.gov.ph/sntpost/frames/april2k2/pg_lb.htm] 